\title{
Ossification of the Femur in Thyroxine-Treated Tadpoles of Rana pipiens ${ }^{1}$
}

\author{
Norman E. Kemp and Judith A. Hoyt \\ Department of Zoology, The University of Michigan, Ann Arbor, Michigan 48104
}

Accepted May 22, 1969

\section{INTRODUCTION}

Bone is an exclusively vertebrate tissue (McLean and Urist, 1955; Urist, 1964; Johnson, 1966) that develops in teleosts and higher vertebrates during the "metamorphic" period (Witschi, 1956) following larval differentiation of connective tissue and cartilage. Both the thyroid and parathyroid glands are intimately related to differentiation and remodeling of bone (Gorbman and Bern, 1962; AsboeHansen, 1963; Young, 1964; Tapp, 1966; Hamburgh, 1968), but precisely how their hormones influence osseous tissue is unknown. How these hormones regulate calcium mobilization and storage in the skeleton (McLean, 1958; Bassett, 1963; Bronner, 1964) is a fundamental aspect of vertebrate morphogenesis.

Extirpation of the thyroid primordium in anuran embryos at the tailbud stage results in excessive larval growth and the arrest of metamorphic changes in the bones of vertebrae and hind limbs (Allen, 1918, 1925; Terry, 1918). Skeletal differentiation resumes in thyroidectomized tadpoles fed thyroid powder (Terry, 1918). Administration of thiourea or thiouracil to larval amphibians mimics thyroidectomy in blocking metamorphosis (Gordon et al., 1945; Steinmetz, 1954). Prolactin likewise is antagonistic to the mechanism by which thyroid hormones stimulate metamorphosis (Etkin and Gona, 1967; Gona, 1967; Brown and Frye, 1969).

Amphibian larvae immersed in solutions of thyroxine (Fox and Irving, 1950; Kaltenbach, 1953; Kuhn and Hammer, 1956; Kollros, 1961) or receiving implants of thyroxine mixed with cholesterol or agar (Kaltenbach, 1953; Kuhn and Hammer, 1956) undergo accelerated differentiation of bones of the skull, vertebral column, and limbs. Thyroxine and triiodothyronine promote maturative changes,

\footnotetext{
'Supported by research grants from the National Science Foundation (GB 4317), the U. S. Public Health Service (GM 05867-10), and the University of Michigan Cancer Research Institute (Project 102).
} 
including bone deposition, in rudiments of chick bones cultured in vitro (Fell and Mellanby, 1955, 1956; Lengemann, 1962; Lawson, 1963). Both thyroxine and parathyroid hormone may induce maturation in explanted cartilaginous bone rudiments of the mouse (Gaillard, 1963).

Electron microscopy has revealed that bone becomes mineralized by deposition of crystals of hydroxyapatite along the collagen filaments of bone matrix (Robinson and Watson, 1952; Fitton-Jackson, 1957; Glimcher, 1960). The possible importance of ground substance in early mineralization is also recognized (Cameron, 1963; Weidmann, 1963; Decker, 1966). There is good evidence that bone crystallites first start to form in separate nucleation centers within the interior of collagen fibrils, not merely around them (Sheldon and Robinson, 1957; Glimcher, 1960). It has been demonstrated that nucleation centers and growing crystallites may be distributed periodically in relation to the repeating bands of collagen (Robinson and Watson, 1952; Fitton-Jackson, 1957; Robinson and Sheldon, 1960; Nylen et al., 1960; Glimcher, 1960; Dudley and Spiro, 1961; Ascenzi et al., 1965; Engström, 1966).

Osteoblasts and osteocytes in bone from various sources (FittonJackson, 1957; Dudley and Spiro, 1961; Baud, 1962; Cameron, 1961; Knese, 1963; Cameron et al., 1964; Decker, 1966; Doty, 1966) have the distinctive characteristics of (1) abundant cisternae of roughsurfaced endoplasmic reticulum (RER) occupying much of the cytoplasm and (2) a well-developed Golgi zone near the nucleus. Osteoid matrix adjacent to osteoblasts appears to be protected from the process of mineralization proceeding deeper in the matrix (Dudley and Spiro, 1961; Weidmann, 1963). How the matrix becomes modified to foster mineralization is a major problem of osteogenesis. The present paper deals with cytological changes in osteoblasts and bone matrix during the metamorphic development induced by treating frog larvae with thyroxine, as previously reported by abstract (Kemp and Hoyt, 1965).

\section{MATERIALS AND METHODS}

Tadpoles of Rana pipiens were raised in the laboratory from embryos obtained by Rugh's method for artificial ovulation and fertilization as modified by Wright and Flathers (1961). Adult frogs were purchased from E. G. Steinhilber, Oshkosh, Wisconsin. Females were induced to ovulate by injection of one fresh female pituitary 
gland intrapleuroperitoneally plus $5 \mathrm{mg}$ of progesterone suspended in corn oil into the dorsal lymph sac. Animals were raised in $11 \times$ 16-inch enamel pans holding about an inch of water previously conditioned by aerating tap water for at least 12 hours. The water was changed three times a week, and animals were fed boiled lettuce after each change.

A stock solution of the sodium salt of $l$-thyroxine, purchased from Calbiochem, was prepared at a concentration of $1.25 \times 10^{-6} \mathrm{M}$ in distilled water and stored in a refrigerator at $10^{\circ} \mathrm{C}$. Tadpoles were treated in groups of five in 4-inch fingerbowls containing $200 \mathrm{ml}$ of thyroxine solution at a concentration of $6.25 \times 10^{-8} M$, made by diluting stock solution with conditioned tap water. Treatment was begun at Taylor-Kollros stage IX, prior to the onset of ossification of the femur. Animals were fed until they stopped eating, usually about 3 days after treatment began. Metamorphic changes in limbs and body shape were obvious by day 4 . Tadpoles could not complete the changeover to air breathing and succumbed to the thyroxine treatment by days $7-10$.

Specimens were fixed at daily intervals after treatment was started. Animals to be stained with alizarin were processed by Mayorga's (1964) technique adapted for our material. Representative stained and cleared specimens were photographed with a vertically mounted Exacta reflex camera, utilizing both reflected and transmitted light. Limbs of specimens to be examined microscopically were excised and fixed in a solution of ice cold, $6.25 \%$ gluteraldehyde buffered with phosphate at $\mathrm{pH} 7.4$, washed in $7.5 \%$ sucrose, postfixed in Caulfield's $1 \%$ osmic acid solution buffered with Veronal at $\mathrm{pH} 7.4$ and containing $0.045 \mathrm{gm}$ of sucrose per milliliter of fixative, dehydrated with ethanol and embedded in Luft's medium-hard mixture of Epon 812 and curing agents. Epon sections were cut with glass knives or with a DuPont diamond knife mounted on an LKB Ultrotome.

Thick sections (ca. $1 \mu$ ) for light microscopy were mounted on glass slides and stained with basic fuchsin (Winkelstein et al., 1963) or with azure B bromide. Photomicrographs were made with a Spencer photomicrographic camera holding $4 \times 5$-inch Panatomic $\mathrm{X}$ film. Thin sections for electron microscopy were mounted on uncoated 200-mesh copper grids. In order to minimize leaching of bone crystals, we followed Boothroyd's (1964) procedure of adding calcium and phosphate ions to the collecting boat for mineralized sections. 
Mounted sections to be stained were transferred to drops of a saturated solution of uranyl acetate on a wax plate and stained for about 2 hours. Excess stain was removed by washing grids in running tap water for $5 \mathrm{~min}$, rinsing in distilled water, and blotting on filter paper. Electron microscopy was performed with an RCA EMU $3 E$ electron microscope operating at $50 \mathrm{kV}$.

\section{RESULTS}

\section{Alizarin Staining}

Tadpoles fixed at Taylor-Kollros stage IX did not show specific staining of the skeleton of the hind limb after exposure to alizarin red $\mathrm{S}$. At stage $\mathrm{X}$ femur and tibiofibula regularly stained with alizarin. Tarsals and metatarsals sometimes stained at stage $\mathrm{X}$, as did also the ilium. These elements always stained at stage XI. Phalanges did not stain until stage XIII. We concluded from these results that at stage IX the femur should be in a preosseous condition; hence this stage should be favorable for testing the influence of thyroxine on ossification.

Results of treating a series of 18 animals with thyroxine at stage IX are illustrated in Figs. 1-3. Figure 1 depicts the limbs and stained limb bones in representative animals fixed 4-8 days after treatment with thyroxine began. The control for day 4 was still at stage IX, whereas the thyroxine-treated specimen at 4 days possessed stained femurs and tibiofibulae. Mium, tarsals, and metatarsals stained in addition to femur and tibiofibula in tadpoles treated 5 or 6 days. Phalanges stained after 7-8 days of exposure to thyroxine. Controls did not progress beyond stage XI during the period of the experiment. Figure 2 shows an untreated animal at stage IX as compared with an 8-day treated specimen (Fig. 3) in which the state of ossification was like that of a normal stage XVIII tadpole.

\section{Light Microscopic Observations}

At stage IX (Fig. 4) the cartilaginous model of the femur has just begun to differentiate from mesenchyme, and perichondrial cells are beginning to elongate in a circumferential direction. By stage $\mathrm{X}$ (Fig. 5) cartilage and perichondrium are clearly delineated. Perichondrial cells are fusiform and closely packed, although distinctly separated from one another by connective tissue matrix. Capillaries are present in the loose connective tissue peripheral to the perichondrial sheath but do not penetrate the sheath itself. By stage XI (Fig. 6) a zone 
INFLUENCE OF L-THYROXINE ( $50 \mu g /$ /iter)

ON DEVELOPMENT OF HIND LIMB

Untreated Controls Doys Thyroxine-Treated
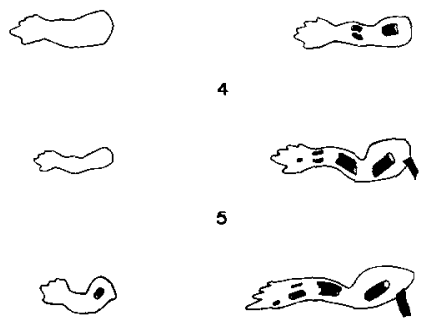

6
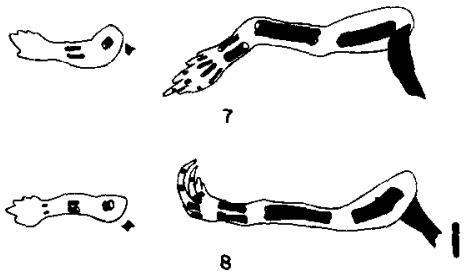

8

Camera lucido drowings of alizarm-stained limbs. $\overline{1 \mathrm{~mm}}$.
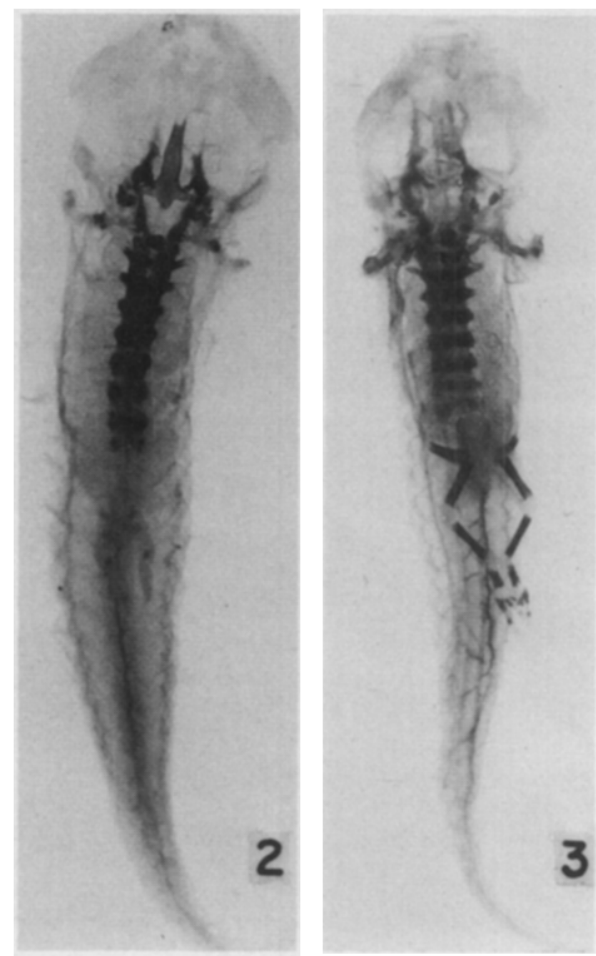

Fig. 1. Camera lucida drawings of alizarin-stained specimens showing differentiation of limb bones in untreated controls and in tadpoles treated with thyroxine for 4-8 days beginning at Taylor-Kollros stage IX. Results described in text.

FIG. 2. Alizarin-stained control specimen at stage IX showing calcified skeletal elements of skull and vertebral column. Cartilaginous rudiments of ilium, femur, and tibiofibula in hind limb are discernible. $\times 3.5$.

Fig. 3. Alizarin-stained experimental tadpole treated 8 days with thyroxine. Ilium, femur, tibiofibula, tarsals, metatarsals, and phalanges are well differentiated. $\times 3.5$.

of osteoid matrix has begun to develop between cartilage and perichondrium. We will use the term "border cells" for the flattened cells that lie along the border between osteoid matrix and cartilage matrix. The border cells appear to be derived from inner perichondrial cells. Perichondrial cells along the outer border of the osteoid matrix have become osteoblasts.

The histological appearance of femurs exposed to thyroxine 1-3 days was like that of the normal femur at stage $\mathrm{X}$ or XI. A specimen fixed on day 4, however (Fig. 7), showed two significant changes: (1) two or three rows of the perichondrial cells nearest to the osteoid 

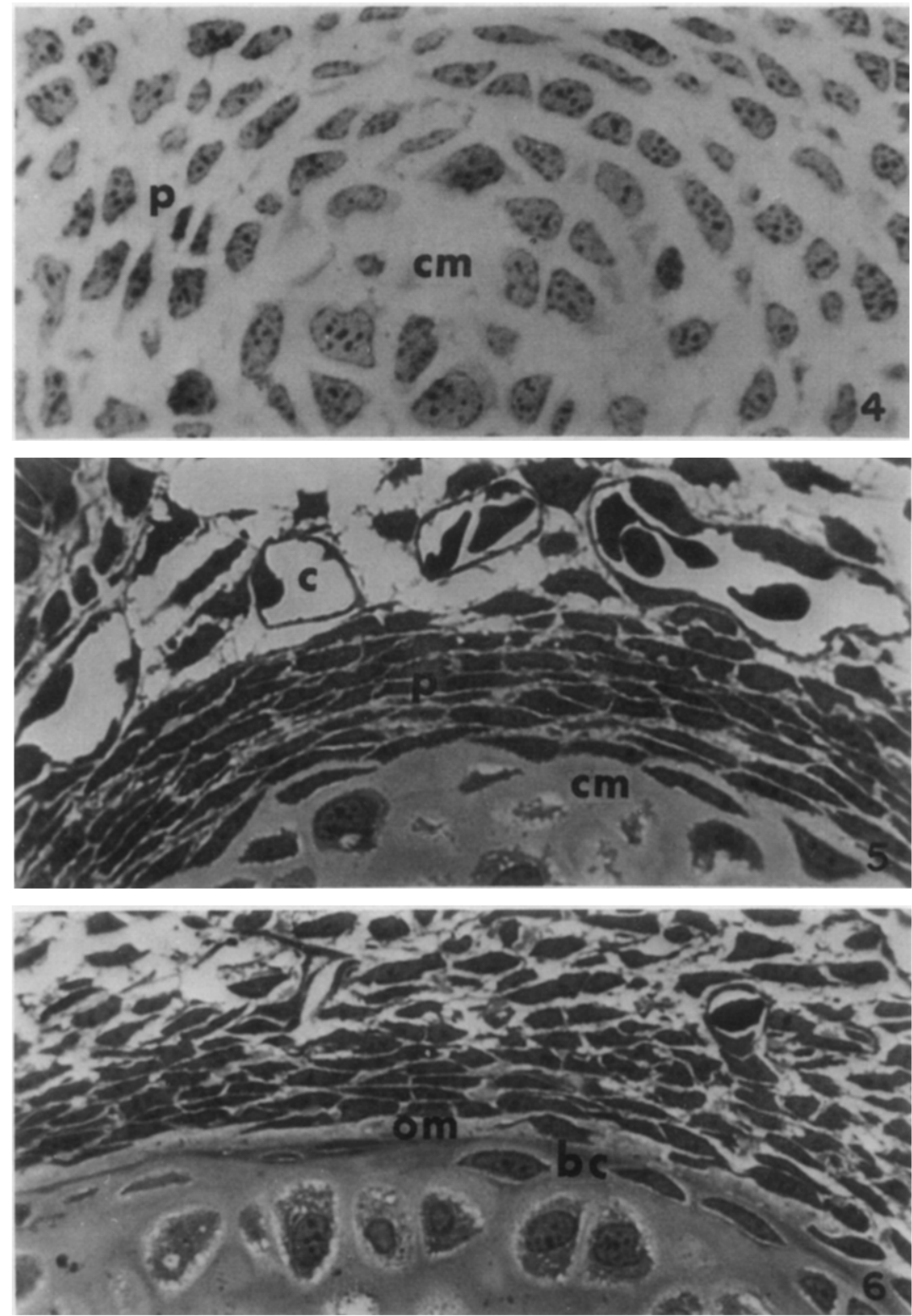

Fig. 4. Section of control femur at stage IX, showing limb mesenchyme organizing into central cartilage cells with prominent matrix $(\mathrm{cm})$ surrounded by perichondrial cells $(p)$ elongating circumferentially. $\times 760$.

Fig. 5. Section of control femur at stage X. Well-differentiated central cartilage with prominent matrix $(\mathrm{cm})$ surrounded by $7-8$ rows of fusiform perichondrial cells $(p)$. Capillaries $(c)$ are restricted to connective tissue outside perichondrium. $\times 760$.

FIG. 6. Section of control femur at stage XI. Osteoid matrix (om) separates cartilage and perichondrium. Flattened "border cells" $(b c)$ lie along the border between osteoid matrix and cartilage. $\times 760$. 
matrix were enlarged; and (2) capillaries lay close to the osteoid matrix among these large cells, which had become osteoblasts. Specimens fixed at 5 and 6 days resembled the 4-day specimen. By 7 days (Fig. 8) several rows of perichondrial cells had become converted into osteoblasts. During conversion the cells lose their fusiform shape and become irregularly rounded or pyramidal. Their altered shape indicates that the matrix between them is not rigid but permits some degree of cell mobility. In a 9-day specimen (Fig. 9) bone matrix entirely surrounded some of the inner osteoblasts, thereby converting them to osteocytes. New osteoid matrix, evidently secreted by more peripheral osteoblasts, had accumulated outside the zone of earlier ossification. This morphology illustrates that periosteal osteogenesis proceeds by activation of successively more peripheral osteoblasts.

The osteogenic changes described for thyroxine-treated tadpoles (Figs. 7-9) are similar to those occurring normally during the period of hindlimb growth between Taylor-Kollros stage IX and stage XVIII. It appears that the action of the hormone on the limb skeleton during the 7-10 days of survival of treated animals is to accelerate changes which usually extend over several weeks. Although we have not followed the normal histological changes during the climax of metamorphosis and after metamorphosis in Rana pipiens, our observations on alizarin-stained specimens indicate that the bones in this species develop as reported by McEwen (1957) for Rana catesbeiana. Sections prepared by Marvin in McEwen's laboratory indicated that bone of the diaphysis in long bones of the bullfrog is purely periosteal. Marrow replaces diaphyseal cartilage, but there is no endochondral ossification. The epiphyses have no separate centers of epiphyseal ossification as in mammals, and remain permanently cartilaginous.

\section{Electron Microscopic Observations}

The boundary between chondroblasts and perichondrial cells in an animal treated with thyroxine for 1 day is illustrated in Fig. 10. Polyribosomes are abundant but endoplasmic reticulum is sparse in the perichondrial cells at this time. Fine collagen filaments permeate the cartilage matrix. Electron-dense material, which we will call "border substance," has accumulated along the perimeter of the cartilage matrix. We do not know the significance of this material. The morphology of cartilage and perichondrium in this 1-day specimen was essentially like that in the normal femur at stage $\mathrm{X}$. 

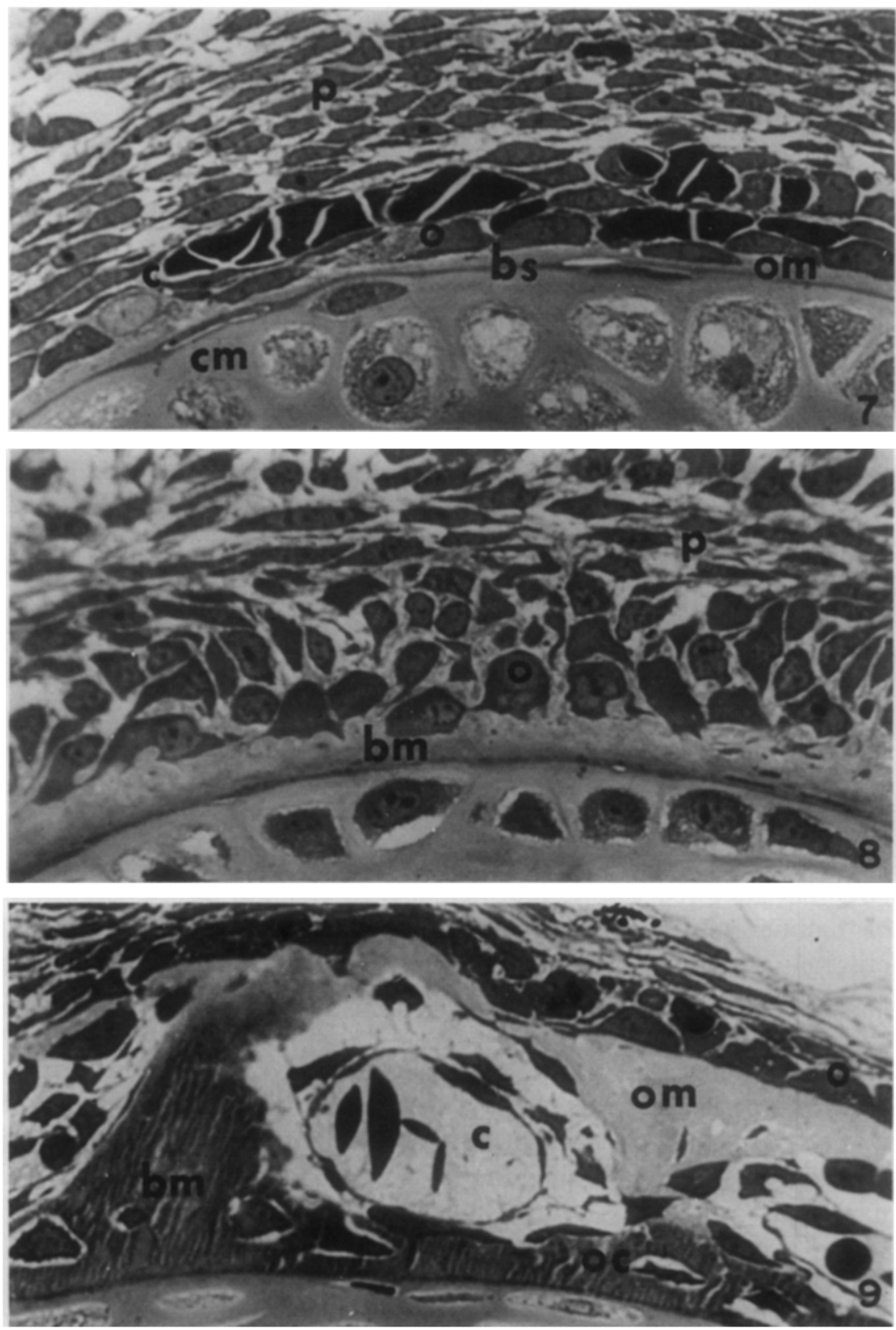

blasts $(o)$. Capillaries (c) lie adjacent to inner layer of osteoblasts. Dense border substance $(\mathrm{bs})$ at boundary between osteoid matrix $(\mathrm{om})$ and cartilage matrix $(\mathrm{cm})$. $\times 760$.

FIG. 8. Section of femur from experimental tadpole treated 7 days with thyroxine. Three or four rows of perichondrial cells have become osteoblasts $(o)$, irregularly rounded or polygonal. More peripheral perichondrial cells $(p)$ are still fusiform. Bone matrix $(b \mathrm{~m})$ between osteoblasts and cartilage is being mineralized at this time. $\times 760$.

FIG. 9. Section of femur from experimental tadpole treated 9 days with thyroxine. Mineralized bone matrix $(\mathrm{bm})$ surrounds original inner osteoblasts, which have thus become osteocytes $(o c)$. New osteoid matrix $(o m)$ peripheral to capillaries $(c)$ is product of peripheral osteoblasts $(o) . \times 760$. 

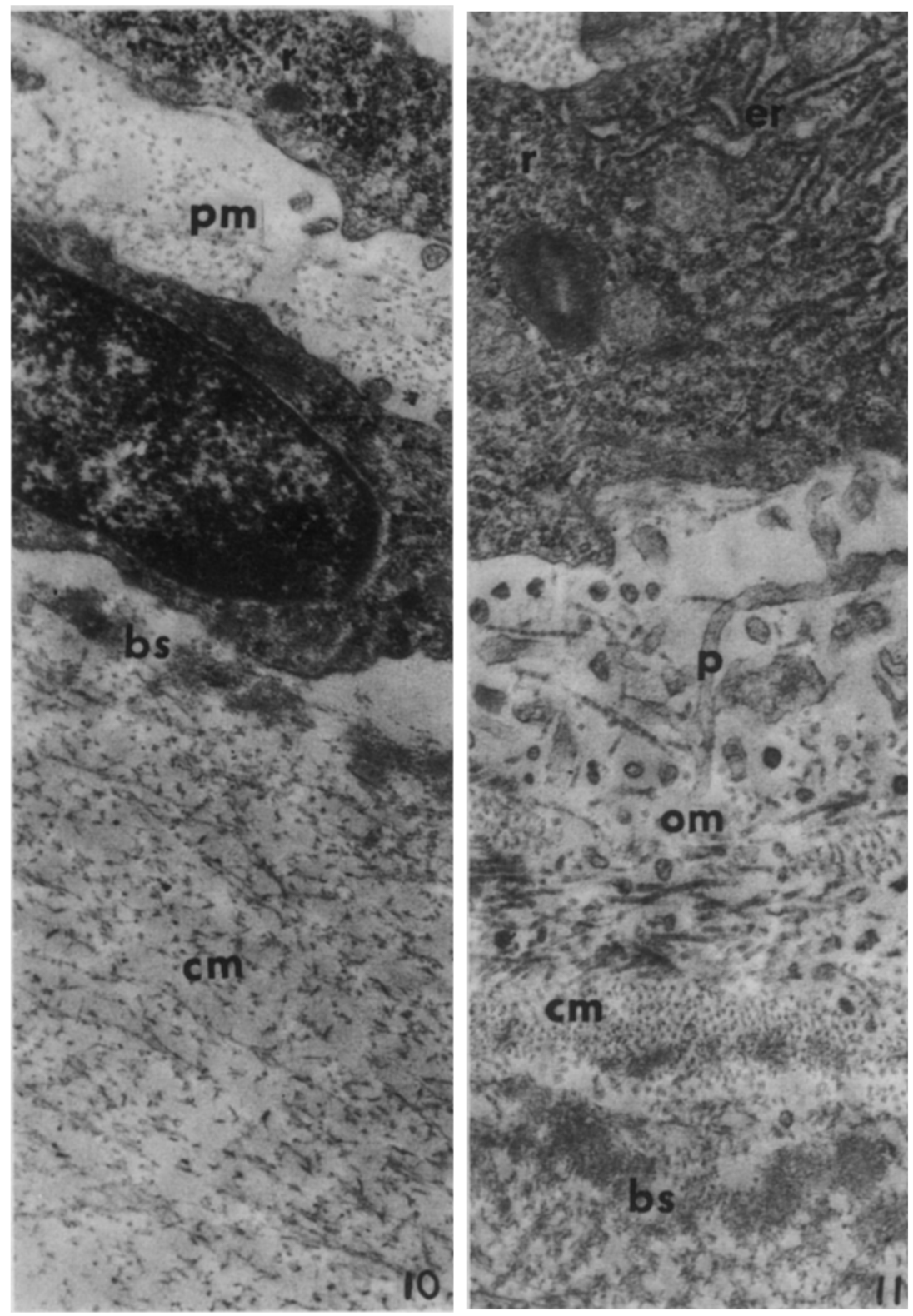

Fig. 10. Electron micrograph of section of femur from tadpole treated 1 day with thyroxine. Cartilage and perichondrium look like those of a normal animal at stage X. Electron-dense border substance (bs) is localized along outer margin of cartilage matrix $(\mathrm{cm})$. Collagen fibrils permeate the cartilage matrix and also the matrix between perichondrial cells $(p m)$. Polyribosomes $(r)$ are abundant within these cells. $\times 31,140$.

Fig. 11. Section of femur from tadpole treated 2 days with thyroxine. Rough endoplasmic reticulum (er) has begun to proliferate in the central cytoplasm of a young osteoblast developing from an inner perichondrial cell. Polyribosomes $(r)$ are still abundant in the more distal cytoplasm. Protoplasmic processes $(p)$ from osteoblast extend into osteoid matrix $(\mathrm{om})$ packed with collagen fibrils. Cartilage matrix $(\mathrm{cm})$ contains finer fibrils and dense border substance $(b s) . \times 25,680$. 
Inner perichondrial cells had already begun to differentiate as osteoblasts in a femur fixed at 2 days (Fig. 11). Cisternae of RER had begun to accumulate in the cytoplasm, and protoplasmic processes were protruding into the newly secreted osteoid matrix. It is apparent that the well-developed collagen fibrils in osteoid matrix have about twice the diameter of the fibrils in cartilage matrix. This 2-day specimen was morphologically similar to the normal femur at stage $\mathrm{XI}$.

The extensive proliferation of RER in an osteoblast of a femur fixed on day 5 is illustrated in Fig. 12. Vesicles which appear to be derived from the Golgi apparatus have also developed by day 5 . Mitochondrial activity is indicated by the elongate form of the mitochondria. Collagen fibrils show regions of fusion in the osteoid matrix of this specimen, but there are no obvious mineralization sites. Possibly fusion of fibrils is a sign of impending mineralization. Sections of protoplasmic processes from osteoblasts are numerous throughout the matrix.

A 6-day specimen (Fig. 13) shows the scattered distribution of mineralization sites where clusters of hydroxyapatite crystals are being deposited. Mineralizing sites are scarce in the outer third of the osteoid matrix but more abundant in the inner two-thirds toward the border of cartilage. Fven at this low magnification one can see that most of the mineralization sites are larger in diameter than the individual fibrils of collagen dispersed throughout the matrix. Some sites, however, have about the same diameter as collagen fibrils. Mineralization appears to be in progress either along single fibrils or in masses of fused fibrils.

Views of increasing magnification of early mineralizing sites in 6day specimens are shown in Figs. 14-16. Nonmineralizing collagen is dispersed throughout the matrix between mineralizing sites. As in the low-power view (Fig. 13), we observe that some sites are the size of individual collagen fibrils and others the width of two or more fibrils. In cross sections of mineralizing fibrils or masses of fused fibrils (Figs. 14-16) it is apparent that hydroxyapatite crystals are forming within the interior of a mineralizing fibril or mass as well as at the periphery. Crystals are always in close association with collagen protofibrils, not dispersed randomly in the ground substance between fibrils.

The earliest observed stage of mineralization is characterized by the appearance of punctate crystals (Figs. 14 and 15), which may 


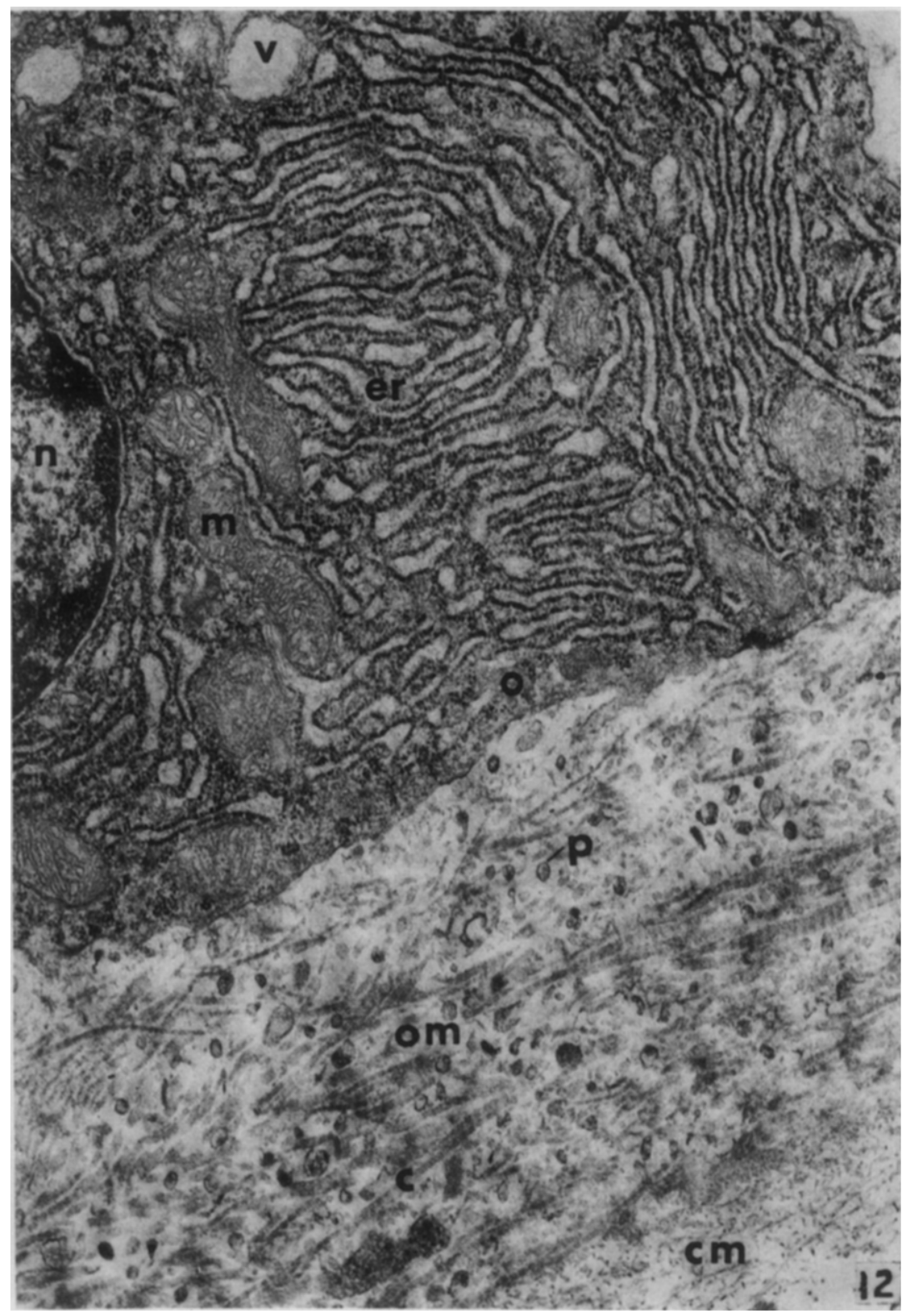

Fig. 12. Section of femur from tadpole treated 5 days with thyroxine. Osteoblast $(o)$ shows central nucleus $(n)$. Cytoplasm contains abundant cisternae of rough endoplasmic reticulum $(\mathrm{er})$, elongate mitochondria $(m)$ and large, smooth-walled vesicles $(v)$, which are probably derived from Golgi apparatus. Osteoid matrix (om) contains numerous protoplasmic processes $(p)$ and is packed with collagen fibrils (c), some of which appear to be fusing. Cartilage matrix $(\mathrm{cm})$ has finer collagen fibrils. $\times 23,555$. 

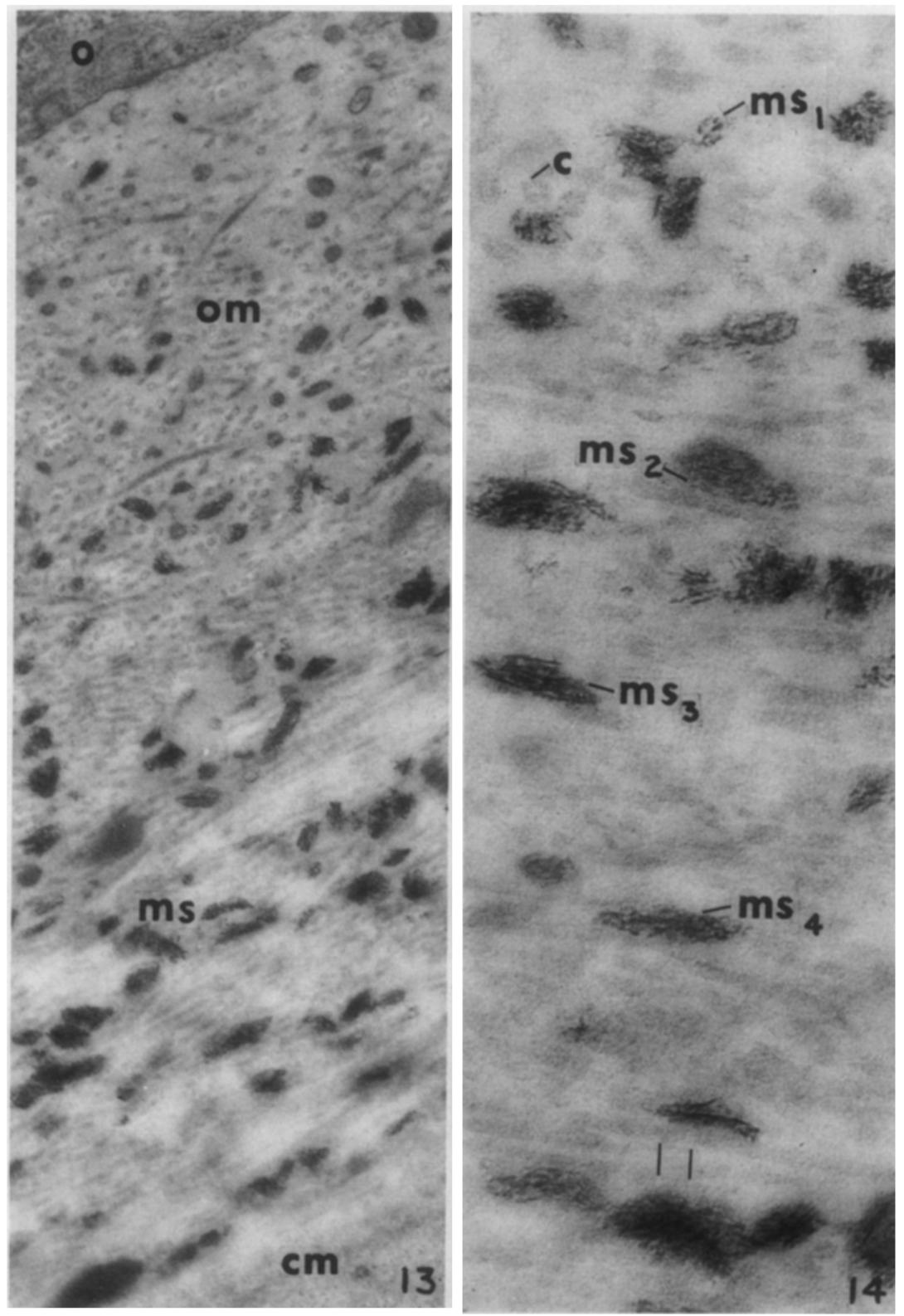

Fig. 13. Section of femur from tadpole 280 treated 6 days with thyroxine, showing osteoid matrix $(\mathrm{om})$ between an osteoblast $(\mathrm{o})$ and cartilage matrix $(\mathrm{cm})$. Mineralization sites ( $m s$ ) for deposition of hydroxyapatite crystals are scattered through the osteoid matrix, but most abundantly in the lower two-thirds. $\times 27,965$.

Fig. 14. Section of femur from tadpole 280 treated 6 days with thyroxine, showing enlarged mineralization sites $\left(m s_{1}-m s_{4}\right)$ at early stages of mineralization. Sites are associated with collagen fibrils $(c)$ either separately $\left(m s_{1}\right)$ or in masses which evidently result from fusion of collagen fibrils $\left(m s_{2}, m s_{3}, m s_{4}\right)$. The smallest crystallites that form within collagen fibrils $\left(m s_{1}\right)$ or masses of fibrils $\left(m s_{2}\right)$ are punctate. These centers elongate and apparently fuse to form needle-shaped crystals $\left(m s_{2}, m s_{3}\right)$. Length of repeating period of collagen bands is shown between parallel lines. $\times 61,600$. 


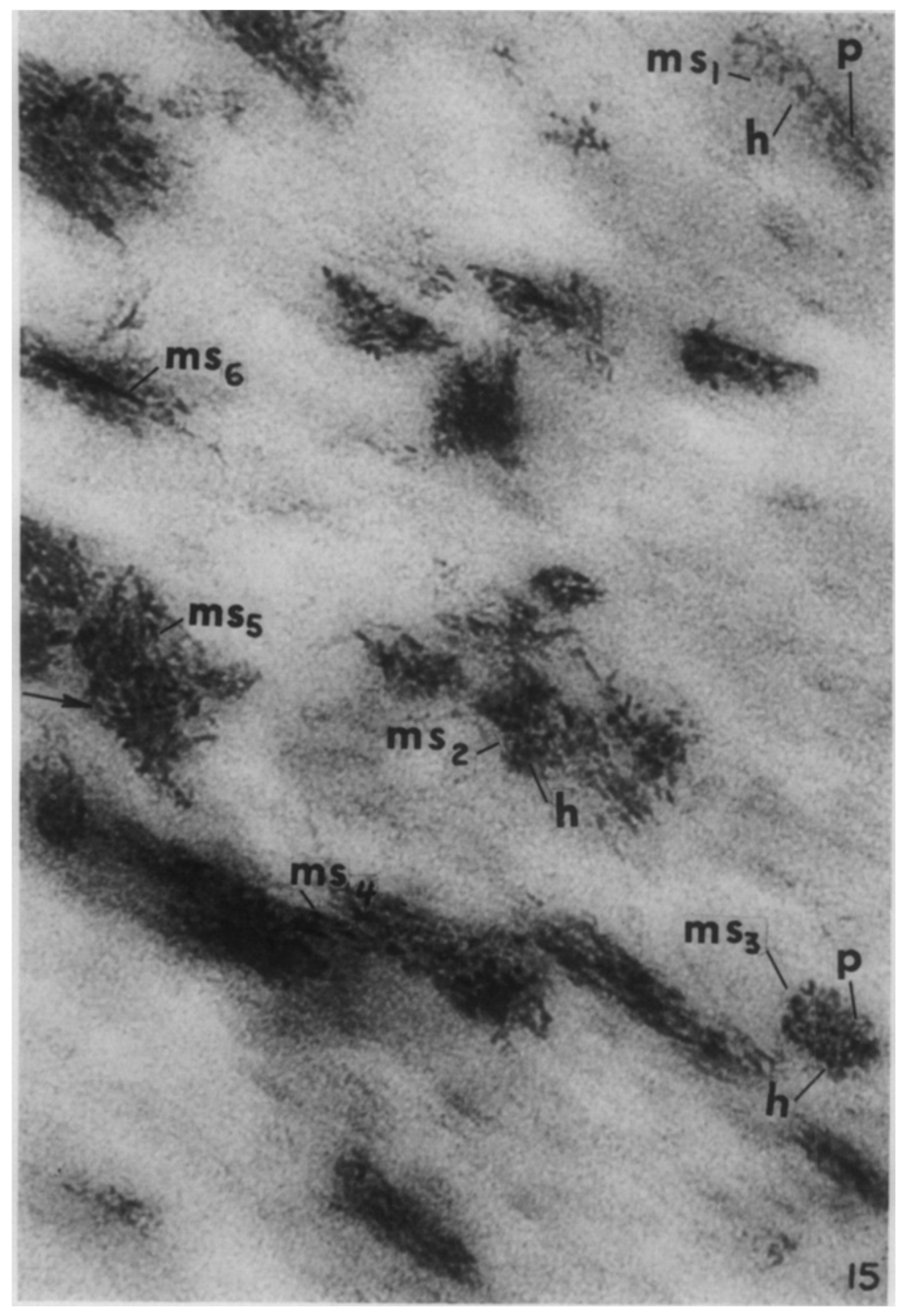

FIG. 15. Section of femur from tadpole 280 treated 6 days with thyroxine, showing early mineralization sites at various stages of development. Punctate, electron-opaque crystallites of hydroxyapatite $(h)$ have begun to appear at an early mineralizing site $\left(m s_{1}\right)$ and show evidence of a periodic distribution along aligned protofibrils $(p)$ of collagen measuring about $35 \AA$ in diameter. Dark crystallites at sites $m s_{2}$ and $m s_{3}$ have attained a width of $50-100 \AA$. Early elongation of crystallites is seen at $m s_{4}$. Alignment of growing crystallites at a particular cross-sectional level of the protofibrils in a mineralizing site $\left(m s_{5}\right)$ is indicated by the arrow. Elongate crystallites may be overlapping at $m s_{6} . \times 144,470$. 


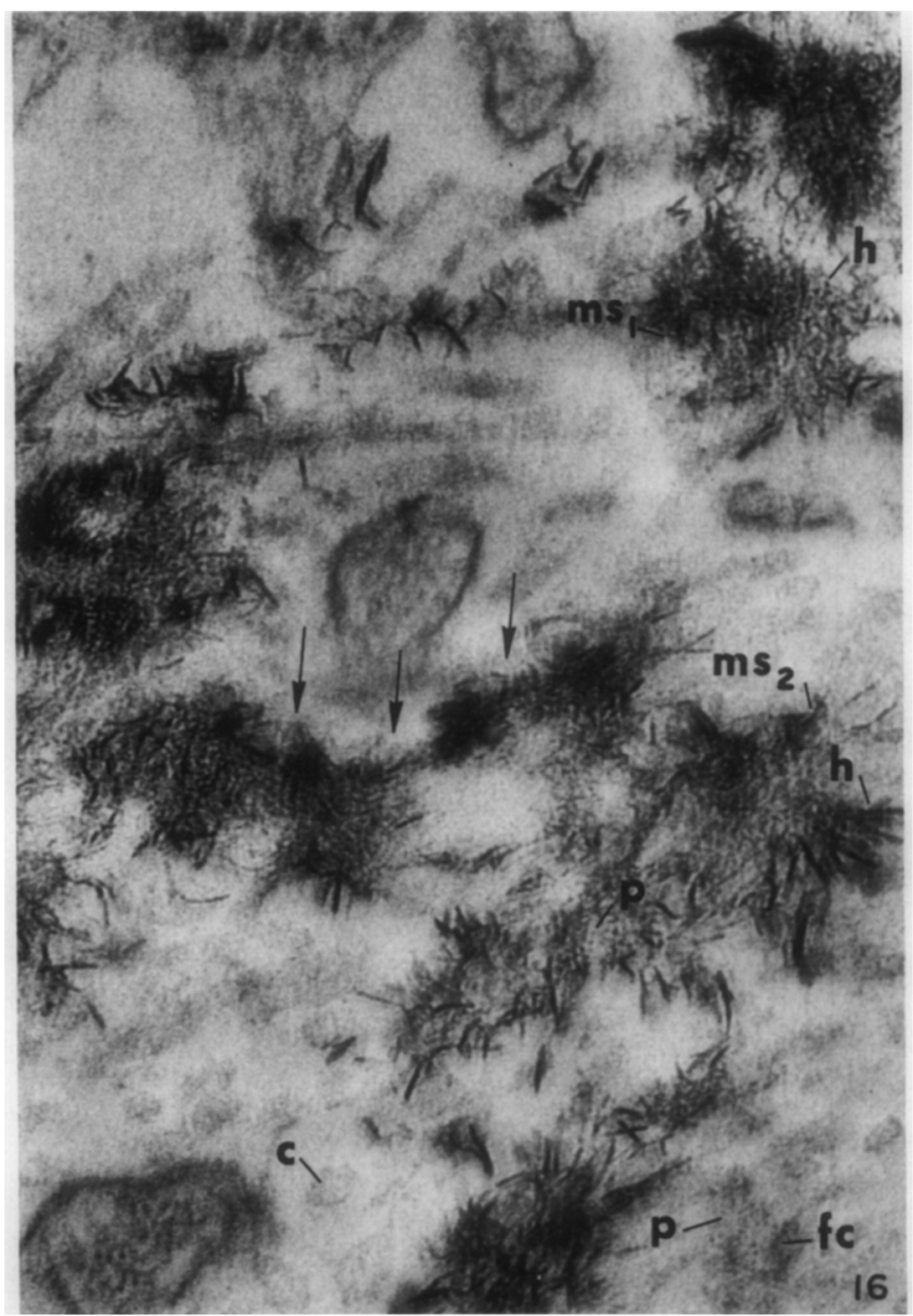

Fig. 16. Section of femur from tadpolc 311 treated 6 days with thyroxine, showin mineralization sites at later stages of growth than those illustrated in Figs. 13-15. Collagen fibrils $(c)$ in nonmineralizing matrix are generally surrounded by noncollagenous zones of protein polysaccharide. A region of fused collagen fibrils $(f c)$ shows close packing of protofibrils $(p)$ and reduction of noncollagenous matrix. Crystallites of hydroxyapatite $(h)$ are interspersed among the protofibrils of mineralizing masses $\left(m s_{1}\right)$ or clustered around the periphery of masses $\left(m s_{2}\right)$. Alignment of punctate and elongating crystallites in bands across the long axis of mineralizing protofibrils is seen at arrows. Elongation of crystallites is in the direction of the longitudinal axis of masses of protofibrils of collagen. $\times 128,990$. 
mark the original nucleation centers for hydroxyapatite crystallization. These early crystals may be distributed in bands along the protofibrils of mineralizing masses (Figs. 15 and 16), but the periodicity of these bands with respect to the intraperiod subbands of collagen (Glimcher, 1960) has not been determined in this investigation.

Needlelike crystals form as the early punctate centers elongate and apparently fuse in the direction of the longitudinal axis of accompanying collagen protofibrils (Figs. 14-16). Most of the crystals do not exceed $640 \AA$, the length of single periods of collagen fibrils. Elongate crystals which appear to exceed this length (Figs. 14 and 15) may actually be two or more crystals with their ends overlapping. Growing sites of mineralization tend to show clustering of hydroxyapatite crystals around the periphery of masses of collagen protofibrils (Fig. 16).

The completion of mineralization involves joining of separate mineralization sites (Figs. 17 and 18). The matrix becomes "fully mineralized" as mineralization sites enlarge and become confluent, thereby eliminating nonmineralized regions. The older two-thirds of the matrix adjacent to cartilage in a specimen treated 9 days with thyroxine shows more advanced mineralization (Fig. 17) than the younger third adjacent to osteoblasts (Fig. 18). Note that in the older region (Fig. 17) the crystallites tend to be oriented circumferentially in the direction of the fibrillar framework of the matrix. Perhaps this orientation results from the tension imposed on the matrix as the femur grows in width.

Mineralizing sites in the newer part of the matrix of a specimen treated 9 days with thyroxine are becoming confluent (Fig. 18). These sites show the polarized organization observed in the isolated sites of the 6-day specimen illustrated in Fig. 16. Hydroxylapatite crystals are clustered around the periphery of individual mineralizing masses, and nonmineralized protofibrils of collagen occupy the interior. Directions of crystallites within and around a mineralizing site may reflect the variable orientations of the separate collagen fibrils contributing to the mass. Another possible explanation is that crystallites become displaced toward the periphery of enlarging sites of mineralization and assume variable secondary orientations upon release from the primary orienting influence of collagen protofibrils. 

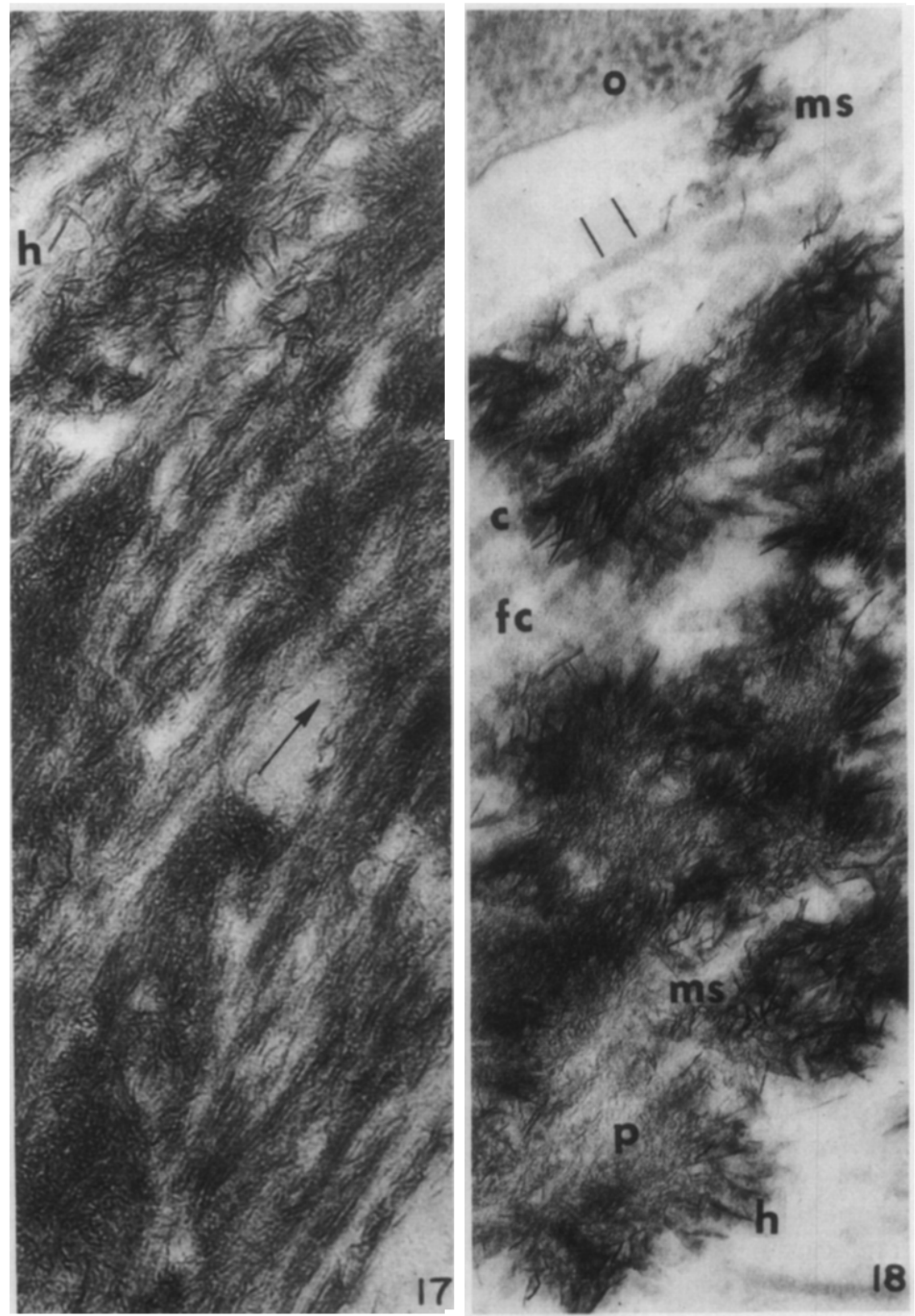

FIG. 17. Section of femur from tadpole 318 treated 9 days with thyroxine, showing region of heavy mineralization in lower two-thirds of bone matrix. Needle-shaped crystals of hydroxyapatite $(h)$ are oriented predominantly in the direction of the arrow, which is parallel to the course of circumferentially oriented collagen protofibrils. $\times 103,835$.

Fig. 18. Section of femur from tadpole 318 treated 9 days with thyroxine, showing enlarged mineralization sites $(m s)$ becoming confluent in outer third of bone matrix adjacent to an osteoblast $(o)$. Collagen fibrils appear either singly $(c)$ or in fused masses $(f c)$ in the matrix adjacent to mineralizing sites. Hydroxyapatite crystals $(h)$ show polarized clustering around central masses of collagen protofibrils $(p)$. Length of repeating period of collagen bands is shown between paralle] lines. $\times 68,565$. 


\section{DISCUSSION}

Tata (1968) has reported that competent tissues of Xenopus laevis larvae treated with thyroid hormones typically pass through a delay of about 2 days before biochemical or morphological changes are detected. We have observed about the same time lag of 2 days before perichondrial cells show fine structural changes indicative of transformation to osteoblasts in the femurs of thyroxine-treated tadpoles of Rana pipiens.

With respect to its role of inducing osteoblastic differentiation, thyroxine may perform any of the variety of functions ascribed to thyroid hormones acting on various cells and tissues: increasing cell permeability (Green and Matty, 1964), uncoupling oxidative phosphorylation (Bronk, 1963; Karlson and Schulz-Enders, 1963), altering mitochondrial membranes and affecting function of respiratory enzymes (Tapley, 1962; Hoch, 1968), chelating metals (Tapley, 1962), stimulating synthesis of nucleic acids (Finamore and Frieden, 1960; Tata, 1968) or of proteins (Paik and Cohen, 1960; Frieden, 1961, 1967; Tatibana and Cohen, 1964; Campbell et al., 1964; Sokoloff et al., 1964; Tata, 1968; Hoch, 1968), and phospholipids (Tata, 1968).

With respect to the influence of thyroxine on mineralization per se, one must account for the interval between the onset of mineralization as indicated by alizarin staining and as judged by visualization of hydroxyapatite crystals electron microscopically. Normally the femur begins to stain selectively with alizarin red $S$ at stages $\mathrm{X}$-XII; and in thyroxine-treated specimens, initially at stage IX, the femur stained by days 2-4. Crystallization of hydroxyapatite, however, was not detected in specimens treated for fewer than 6 days. Alizarin is considered to be an indicator of mineralization because of its property of forming lakes with insoluble deposits of calcium carbonate or calcium phosphate (Pearse, 1960). Early onset of alizarin staining may be related to the observed intracellular changes in osteoblasts or to some early modification of the osteoid matrix. Possibly the electron-dense border substance detectable by stage XI (Fig. 6) and in specimens treated only 1-2 days (Figs. 10 and 11) stains with alizarin.

According to Glimcher $(1960,1966)$, phosphorylation of collagen is probably the initial step in mineralization. Calcification and nucleation of hydroxyapatite crystals would begin at phosphorylating sites, if Glimcher's hypothesis is correct. An altemative view, sup- 
ported by Sobel and co-workers (Bronner, 1964), is that calcium binding is the initial step in establishment of nucleation centers. This view holds that calcium activates collagen to interact with sulfated mucopolysaccharides or mucoproteins of the ground substance during mineralization. Evidence that chondroitin sulfate by itself or in combination with collagen is responsible for nucleation of hydroxyapatite has been reviewed by Weidmann (1963) and Cameron (1963). Decker (1966) has described "initial aggregations of apatite crystals appearing independent of collagen," although he recognizes that these aggregations may result from "factors existing at nucleation sites which in combination with the underlying collagen may initiate the development of crystals."

Our observations do not support Decker's (1966) contention that aggregations of bone crystals develop independently of collagen fibrils. The fibrillar structure of collagen is obscured at mineralizing sites, but nevertheless persists. Robinson and Watson (1952, 1955) observed that individual collagen fibrils appear more closely packed after mineralization than before. Since collagen fibrils remain intact during mineralization, Robinson (1966) has concluded that bone crystals displace water in the osteoid matrix. Close packing and fusion of collagen fibrils at mineralizing sites are presumptive evidence that ground substance is being depolymerized and eliminated from the space surrounding the fibrils at these sites.

Dudley and Spiro (1961) have suggested that the cell processes protruding into the osteoid matrix from osteoblasts may be an indication that these cells "preside over the state of the polymerization of the matrix," possibly by affecting the state of polymerization of the acid mucopolysaccharides in the interfiber substance of the osteoid matrix. Such osteoblastic processes are abundant in the matrix of the frog femur before mineralization sites become obvious (Figs. 11 and 12) but disappear as the matrix mineralizes (Figs. 1318). Perhaps these processes cytolyze and yield hydrolases to the matrix.

One prominent theory (Glimcher, 1960) is that the collagen of nonmineralized connective tissues is protected from mineralization by the highly polymerized mucoproteins (protein-mucopolysaccharide complexes) of the ground substance. The theory holds that depolymerization of ground substance may release collagen from the inhibitory properties of ground substance and thereby lead to active nucleation of hydroxyapatite. Calf cartilage contains a depolymerase capable of degrading protein polysaccharide extracted from cartilage 
(Dziewiatkowski, 1966). Hyaluronidase and collagenase evidently participate in growth and resorption of dermal connective tissue in the tadpole tailfin (Lapiere and Gross, 1963; Lapiere, 1966; Eisen and Gross, 1966). Various mammalian tissues, including bone, also produce collagenase (Woods and Nichols, 1965). We speculate that thyroxine influences mineralization by stimulating osteoblasts to produce depolymerases which render osteoid matrix mineralizable. Whether such enzymes are produced by osteoblasts of the frog skeleton has not yet been demonstrated.

Our observations on nucleation and growth of hydroxyapatite crystals are in general agreement with those of Ascenzi et al. (1965). These investigators have described early nucleation centers as "very small particles or spots" no greater than $10 \AA$ at first. These elongate and fuse to form linear or needle-shaped crystallites spanning band regions and attaining a maximum diameter of $40-45 \AA$. We have confirmed the presence of separate centers that appear to elongate and fuse to form long, narrow crystals of hydroxyapatite. We have also observed a repeating pattern of nucleation along collagen fibrils (Figs. 15 and 16) similar to that reported by Fitton-Jackson (1957), Nylen et al. (1960), and Glimcher (1960). Further study is necessary to establish the relationship between early nucleation centers and the subbands of collagen fibrils in the frog skeleton.

As mineralization sites enlarge (Figs. 16-18), it is clear that hydroxyapatite crystals are not distributed uniformly within a given site. Usually at enlarged sites the hydroxyapatite crystals are clustered around the periphery and nonmineralized protofibrils of collagen occupy the interior. This morphology could result (1) if mineralization is restricted in the interior of a mass of fusing collagen fibrils, (2) if the interior of an enlarged site undergoes selective demineralization, or (3) if crystals are displaced toward the periphery as a mineralization site grows. The third alternative might be an application of Steinberg's (1964) principle that objects with differing strengths of surface adhesiveness tend to segregate from one another. In this instance the greater adhesiveness of collagen fibrils might account for their segregation in the interior of a mineralizing mass.

\section{SUMMARY}

Tadpoles of Rana pipiens at Taylor-Kollros stage IX were treated by immersion in a thyroxine solution at a concentration of $6.25 \times$ $10^{-8} M$. Hindlimbs developed precociously, and alizarin-stained 
specimens showed that treatment with thyroxine induced accelerated ossification of limb bones.

Light microscopy of thick Epon sections showed that cartilage and perichondrium were beginning to organize in the femur of normal animals at stage IX and had become separated by a narrow zone of osteoid matrix by stage XI. After 4 days of exposure to thyroxine, inner perichondrial cells had enlarged to become osteoblasts bordering a prominent zone of osteoid matrix. By 9 days of treatment some inner osteoblasts were entirely surrounded by bone matrix and thus had become osteocytes.

Electron microscopy revealed that rough endoplasmic reticulum began to accumulate in osteoblasts by the second day of treatment. Fusion of collagen fibrils was observed in the osteoid matrix of a specimen treated for 5 days. Deposition of hydroxyapatite crystals along collagen protofibrils in scattered mineralization sites began after 6 days of treatment. Mineralized sites grew and became confluent, so that by 9 days the lower two-thirds of the bone matrix was almost completely mineralized. Enlarged mineralization sites at 9 days usually were organized with collagen protofibrils in the interior and hydroxyapatite crystals clustered around the periphery of the mineralizing mass.

Thyroxine appears to stimulate differentiation of osteoblasts from perichondrial cells. The hormone may stimulate osteoblasts to secrete depolymerases which prepare osteoid matrix for mineralization along collagen fibrils.

We wish to acknowledge the assistance of Mrs. Nancy L. Istock and Dr. Jae Ho Park during the progress of this work.

\section{REFERENCES}

ALLEN, B. M. (1918). The results of thyroid removal in the larvae of Rana pipiens. J. Exptl. Zool. 24, 499-519.

Allen, B. M. (1925). The effects of extirpation of the thyroid and pituitary glands upon the limb development of anurans. J. Exptl. Zool. 42, 13-30.

Asboe-Hansen, G. (1963). The hormonal control of connective tissue. Intern. Rev. Connective Tissue Res. 1, 29-61.

Ascenzi, A., Bonucci, E., ANd Bocciarelli, D. S. (1965). An electron microscope study of osteon calcification. J. Uttrastruct. Res. 12, 287-303.

BASSETT, C. A. (1963). Environmental and cellular factors regulating osteogenesis. In "Bone Biodynamics" (H. M. Frost, ed.), pp. 233-244. Little, Brown, Boston, Massachusetts.

Baun, C. A. (1962). Morphologie et structure inframicroscopique des ostéocytes. Acta Anat. 51, 209-225. 
Boothroyd, B. (1964). The problem of demineralisation in thin sections of fully calcified bone. J. Cell Biol. 20, 165-173.

Bronk, J. R. (1963). Thyroid hormones: control of terminal oxidation. Science 141, 816-818.

Bronner, F. (1964). Dynamics and function of calcium. In "Mineral Metabolism" (C. L. Comar and F. Bronner, eds.), Vol. 2, Part A, pp. 341-444. Academic Press, New York.

Brown, P., AND Frye, B. E. (1969). Effects of prolactin and growth hormone on growth and metamorphosis of tadpoles of the frog, Rana pipiens. Gen. Comp. Endocrinol. in press.

Cameron, D. A. (1961). The fine structure of osteoblasts in the metaphysis of the tibia of the young rat. J. Biophys. Biochem. Cytol. 9, 583-595.

Cameron, D. A. (1963). The fine structure of bone and calcified cartilage. A critical review of the contribution of electron microscopy to the understanding of osteogenesis. Clin. Orthopaed. Related Res. 26, 199-228.

Cameron, D. A., Paschall, H. A., and Robinson, R. A. (1964). The ultrastructure of bone cells. In "Bone Biodynamics" (H. M. Frost, ed.), pp. 91-104. Little, Brown, Boston, Massachusetts.

Campbell, P. L., Deibler, G. E., Gelber, S., and Sokoloff, L. (1964). Comparative effects of various analogues of thyroxine on amino acid incorporation into protein. Endocrinology 75, 304-311.

DECKER, J. D. (1966). An electron microscopic investigation of osteogenesis in the embryonic chick. Am. J. Anat. 118, 591-614.

Doty, S. B. (1966). The electron microscopy of bone cells. Birth Defects, Natl. Found. $2,45-49$.

Dudley, H. R., ANd SpIRo, D. (1961). The fine structure of bone cells. J. Biophys. Biochem. Cytol. 11, 627-649.

Dziewiatkowski, D. D. (1966). Role of proteinpolysaccharides in calcification. Birth Defects, Natl. Found. 2, 31-34.

Eisen, A. Z., AND Gross, J. (1966), 'I'he role of epithelium and mesenchyme in the production of a collagenolytic enzyme and a hyaluronidase in the anuran tadpole. Develop. Biol. 12, 408-418.

ENGSTro̊m, A. (1966). Apatite-collagen organization in calcified tendon. Exptl. Cell. Res. 43, 241-245.

Etkin, W., ANd Gona, A. G. (1967). Antagonism between prolactin and thyroid hormone in amphibian development. J. Exptl. Zool. 165, 249-258.

Fell, H. B., and Mellanby, E. (1955). The biological action of thyroxine on embryonic bones grown in tissue culture. J. Physiol. (London) 127, 427-447.

Fell, H. B., ANd Mellanby, E. (1956). The effect of 1-triiodothyronine on the growth and development of embryonic chick limb-bones in tissue culture. J. Physiol. (London) 133, 89-100.

Finamore, F. J., and Frieden, E. (1960). Nucleic acids and induced metamorphosis. J. Biol. Chem. 235, 1751-1755.

FrrTon-JACKson, S. (1957). The fine structure of developing bone in the embryonic fowl. Proc. Roy. Soc.B146, 270-280.

Fox, E., and Inving, J. T. (1950). The effect of thyroid hormone on the ossification of the femur in Xenopus laevis tadpoles. So. African J. Med. Sci. 15, 11-14. 
Frieden, E. (1961). Biochemical adaptation and anuran metamorphosis. Am. Zoologist 1, 115-149.

FrIEDEN, E. (1967). Thyroid hormones and the biochemistry of amphibian metamorphosis. Recent Progr. Hormone Res. 23, 139-186.

GaILlaRd, P. J. (1963). Observations on the effect of thyroid and parathyroid secretions on explanted mouse radius rudiments. Develop. Biol. 7, 103-116.

GLIMCHER, M. J. (1960). Specificity of the molecular structure of organic matrices in mineralization. In "Calcification in Biological Systems" (R. F. Sognnaes, ed.), pp. 421-487. Am. Assoc. Advan. Sci. Publ. No. 64, Washington, D. C.

Glimcher, M. J. (1966). The ultrastructural organization of bone and the mechanism of calcification. Birth Defects, Natl. Found. 2, 50.

Gorbman, A., and Bern, H. A. (1962). "A Textbook of Comparative Endocrinology." Wiley, New York.

GonA, A. G. (1967). Prolactin as a goitrogenic agent in Amphibia. Endocrinology 81, 748-754.

Gornon, A. S., Gor.dsmith, E. D., and Charipper, H. A. (1945). The effects of thiourea on amphibian development. Growth 9, 19-41.

GrEEN, K., and MATTY, A. J. (1964). The effect of thyroid hormones on water permeability of the isolated bladder of the toad Bufo bufo. J. Endocrinol. 28, 205-211.

HamburGH, M. (1968). An analysis of the action of thyroid hormone on development based on in vivo and in vitro studies. Gen. Comp. Endocrinol. 10, 198-213.

HocH, F. L. (1968). Biochemistry of hyperthyroidism and hypothyroidism. Postgrad. Med. J. 44, 347-362.

Johnson, L. C. (1966). The kinetics of skeletal remodeling. A further consideration of the theoretical biology of bone. Birth Defects, Natl. Found. 2, 66-142.

KALTENBACH, J. C. (1953). Local action of thyroxine on amphibian metamorphosis. I. Local metamorphosis in Rana pipiens larvae effected by thyroxin-cholesterol implants. J. Exptl. Zool. 122, 41-51.

Karlson, P., and Schulz-Enders, A. (1963). Uber die Wirkung des Thyroxins auf die oxydative Phosphorylierung in Insektmitochondrien. Gen. Comp. Endocrinol. 3, $111-119$.

KEMP, N. E., and Hoyt, J. A. (1965). Influence of thyroxine on ossification of the femur in Rana pipiens. J. Cell Biol. 27, 51.A.

KNEsE, K. H. (1963). Zell- und Faserstruktur des Knochengewebes. Acta Anat. 53, 369-394.

Kollros, J. J. (1961). Mechanisms of amphibian metamorphosis: hormones. Am. Zoologist 1, 107-114.

KunN, O., and Hammer, H. O. (1956). Über die Einwirkung des Schilddrüsenhormons auf die Ossifikation. Experientia 12, 231-233.

LAPIERE, C. M. (1966). Remodeling of the bone matrix. In "Calcified Tissues 1965. Proceedings of the Third European Symposium on Calcified Tissues Held at Davos." (H. Fleisch, H. J. J. Blackwood, and M. Owen, eds.), pp. 20-32. Springer, New York.

LAPIERE, C. M., and Gross, J. (1963). Animal collagenase and collagen metabolism. In "Mechanisms of Hard Tissue Destruction" (R. F. Sognnaes, ed.), pp. 663-694. Am. Assoc. Advan. Sci. Publ. No. 75, Washington, D.C.

Lawson, K. (1963). The differential growth-response of embryonic chick limb-bone rudiments to triiodothyronine in vitro. III. Hormone concentration. J. Embryol. Exptl. Morphol. 11, 383-398. 
Lengemann, F. W. (1962). Effects of thyroxine upon strontium and calcium metabolism of embryonic bone grown in vitro. Endocrinology 70, 774-780.

MAYORGA, H. (1964). Metodo rapido para transparentar anfibios y colorear esqueletos. Caribbean J. Sci. 4, 323-325.

McLean, F. C. (1958). The ultrastructure and function of bone. Science 127, 451-456.

McLean, F. C., and Urist, M. R. (1955). "Bone. An Introduction to the Physiology of Skeletal Tissue." Univ. of Chicago Press, Chicago, Illinois.

McEwen, R. S. (1957). "Vertebrate Embryology," 4th ed., p. 254. Holt, New York.

NyLen, M. U., ScotT, D. B., and Mosley, V. M. (1960). Mineralization of turkey leg tendon. II. Collagen-mineral relations revealed by electron and X-ray microscopy. In "Calcification in Biological Systems" (R, F, Sognnaes, ed.), pp. 129-142. Am. Assoc. Advan. Sci. Publ. No. 64, Washington, D.C.

PaIK, W. K., and CoHEN, P. P. (1960). Biochemical studies on amphibian metamorphosis. I. The effect of thyroxine on protein synthesis in the tadpole. J. Gen. Physiol. 43, 683-696.

Pearse, A. G. E. (1960). "Histochemistry Theoretical and Applied," 2nd ed., p. 688. Little, Brown, Boston, Massachusetts.

Robinson, R. A. (1966). The structural organization of bone tissue. Birth Defects, Natl. Found. 2, 40-44.

Robinson, R. A., and Sheldon, H. (1960). Crystal-collagen relationships in healing rickets. In "Calcification in Biological Systems" (R. F. Sognnaes, ed.), pp. 261-279. Am. Assoc. Advan. Sci. Publ. No. 64, Washington, D.C.

Robinson, R. A., and Watson, M. L. (1952). Collagen-crystal relationships in bone as seen in the electron microscope. Anat. Record 114, 383-409.

Robinson, R. A., and Watson, M. L. (1955). Crystal-collagen relationships in bone as observed in the electron microscope. III. Crystal and collagen morphology as a function of age. Ann. N.Y. Acad. Sci. 60, 596-628.

Sheldon, H., and Robinson, R. A. (1957). Electron microscope studies of crystalcollagen relationships in bone. IV. The occurrence of crystals within collagen fibrils. J. Biophys. Biochem. Cytol. 3, 1011-1016.

Sokoloff, L., Francis, C. M., and Campbell, P. L. (1964). Thyroxine stimulation of amino acid incorporation into protein independent of any action on messenger RNA synthesis. Proc. Natl. Acad. Sci. U.S. 52, 728-736.

Steingerg, M. S. (1964). The problem of adhesive selectivity in cellular interactions. In "Cellular Membranes in Development" (M. Locke, ed.), pp. 321-366. Academic Press, New York.

Steinmetz, C. H. (1954). Some effects of thyroxine and antithyroid compounds on tadpoles and their relation to hormonal control of growth. Physiol. Zool. 27, 28-40.

TAPLEY, D. F. (1962). The mechanism of action of thyroid hormone. Am. Zoologist 2, 373-378.

TAPP, E. (1966). The effects of hormones on bone in growing rats. J. Bone Joint Surg. 48B, 526-531.

TAtA, J. R. (1968). Early metamorphic competence of Xenopus larvae. Develop. Biol. 18, 415-440.

Tatibana, M., and Cohen, P. P. (1964). Synthesis of carbamyl phosphate synthetase in liver slices from thyroxine-treated tadpoles. J. Biol. Chem. 239, 2905-2909.

Terry, G. S. (1918). Effects of the extirpation of the thyroid gland upon ossification in Rana pipiens. J. Exptl. Zool. 24, 567-587.

URIST, M. R. (1964). Further observations bearing on the bone-body fluid continuum: 
composition of the skeleton and serums of cyclostomes, elasmobranchs, and bony vertebrates. In "Bone Biodynamics" (H. M. Frost, ed.), pp. 151-179. Little, Brown, Boston, Massachusetts.

Weidmann, S. M. (1963). Calcification of skeletal tissues. Intern. Rev. Connective Tissue Res. 1, 339-377.

Winkelstein, J., Menefee, M. G., and Bell, A. (1963). Basic fuchsin as a stain for osmium-fixed, Epon-embedded tissue. Stain Technol. 38, 202-204.

WITSCHI, E. (1956). "Development of Vertebrates," p. 8. Saunders, Philadelphia, Pennsylvania.

Woods, J. F., and Nichols, G., JR. (1965). Collagenolytic activity in rat bone cells. Characteristics and intracellular location. J. Cell Biol. 26, 747-758.

Wright, P. A. and Flathers, A. R. (1961). Facilitation of pituitary induced frog ovulation by progesterone in early fall. Proc. Soc. Exptl. Biol. Med. 106, 346-347.

YounG, R. W. (1964). Specialization of bone cells. In "Bone Biodynamics" (H. M. Frost, ed.), pp. 117-139. Little, Brown, Boston, Massachusetts. 